\title{
Evaluación de la calidad docente y promoción del profesorado (VII). Legislación universitaria española (e): modificación de la Ley Orgánica de Universidades. Profesorado contratado permanente (2004-2008)
}

\author{
J. Carreras
}

Resumen. La Ley Orgánica de Modificación de la Ley Orgánica de Universidades (LOMLOU), promulgada el año 2007, incluyó disposiciones referentes al profesorado contratado doctor (PCD) que supusieron la consolidación de la vía laboral como alternativa a la vía funcionarial en la carrera universitaria. La Ley estableció que la contratación de los PCD sería de carácter indefinido y con dedicación a tiempo completo, determinó que dichos profesores tenían plena capacidad docente e investigadora, reconoció su condición de elegibles para los órganos unipersonales de gobierno (salvo para el cargo de rector), les atribuyó voto ponderado en la constitución del claustro universitario y en la elección de rector y, mediante modificación de la Ley General de Sanidad, determinó que podría establecerse vinculación de plazas asistenciales con plazas de PCD. Por lo que respecta a los requisitos para acceder a una plaza de PCD, la LOMLOU suprimió la necesidad de acreditar tres años de actividad docente e investigadora, establecida por la LOU, pero mantuvo como requisito una evaluación positiva por parte de un órgano externo (acreditación). En este artículo se analizan comparativamente los procesos de acreditación desarrollados por la Agencia Nacional de Evaluación de la Calidad y Acreditación (ANECA) y por los órganos de evaluación establecidos por las diversas comunidades autónomas, así como los concursos de acceso a las plazas convocadas por las universidades. Además, se describen las características de las diversas figuras de PCD establecidas por las comunidades autónomas.

Palabras clave. Contratación de profesorado doctor. Legislación universitaria española.
Evaluation of teaching and faculty promotion (VII). University Spanish legislation (e): modification of the Organic Law of Universities. Recruited staff with indefinite contract (2004-2005)

Summary. The Organic Law of Modification of the Organic Law of Universities (LOMLOU), promulgated the year 2007, included referring dispositions to the recruited professors with doctorate qualification (PCDs) that supposed the consolidation of the direct contracting way as alternative to the way functionarial in the academic career. The Law established that the contract of the PCDs would be indefinite and with full-time dedication. Determined that these professors had full autonomy in teaching and research, recognized their condition of eligible for the individual organs of government (save for the charge of Rector) and attributed them balanced vote in the University Cloister and in the election of Rector. Furthermore, by means of modification of the General Law of Health, the LOMLOU determined that could be established linking of welfare positions with positions of PCD. For which it concerns to the requirements to achieve to a position of $P C D$, the Law suppressed the need to accredit three years of teaching and researcher, established by the previous Law of Universities; but maintained as requirement a positive evaluation of teaching and research by an external assessment body (accreditation). This article analyzes comparatively the processes of accreditation developed by the National Agency of Evaluation of the Quality and Acreditation (ANECA) and by the assessment bodies specified by the Regional Autonomous Community laws, as well as the recruitment processes developed by the universities. Besides, the characteristics of the diverse figures of $P C D$ established by the Autonomous Communities are described.

Key words. Appointment of the recruited staff with doctorate qualification. University Spanish legislation.
Departamento de

Ciencias Fisiológicas I. Facultad de Medicina. Universitat de Barcelona. Barcelona, España.

Correspondencia Dr. Josep Carreras Barnés Departamento de Ciencias Fisiológicas I. Facultad de Medicina. Universitat de Barcelona. Casanova, 143. E-08036 Barcelona.

Fax +34 934035882.

E-mail

jcarreras@ub.edu

Nota

La redacción del artículo finalizó en julio del 2009, por lo que no contiene información ulterior al año 2008. 


\section{Introducción}

Como comentamos en el artículo anterior [1], el gobierno del Partido Socialista Obrero Español (PSOE) surgido de las elecciones generales del año 2004, en cumplimiento de su programa electoral, presentó un primer anteproyecto de ley de modificación de la Ley Orgánica de Universidades (LOU) [2] a finales de octubre del año 2005 [3]. El documento recibió amplias críticas por parte de gobiernos autonómicos, del Partido Popular (PP), de las organizaciones sindicales, de asociaciones de profesores universitarios y de la Conferencia de Rectores de las Universidades Españolas (CRUE), que presentaron numerosas enmiendas. Renovada la dirección del Ministerio de Educación y Ciencia (MEC), en mayo del año 2006, éste dio a conocer una nueva versión del anteproyecto de ley [4] que recogió algunas de las enmiendas presentadas. A finales del mes de junio, el Consejo de Ministros aprobó un nuevo texto del anteproyecto de ley [5] que, previo informe del Consejo de Estado [6], dio origen al texto definitivo del Proyecto de Ley Orgánica que, con fecha 1 de septiembre, fue aprobado por el Consejo de Ministros y remitido a las Cortes [7]. Cumplida la tramitación parlamentaria, el 29 de marzo del año 2007 tuvo lugar la ratificación definitiva de la Ley por el Congreso de los Diputados con el voto afirmativo de todos los grupos parlamentarios con la única excepción del PP, y el texto se publicó en el Boletín Oficial del Estado el día 13 del mes de abril [8].

En este artículo comentamos los cambios introducidos por la Ley Orgánica de Modificación de la Ley Orgánica de Universidades (LOMLOU) en la normativa referente al profesorado contratado permanente y sus repercusiones en la selección de éste.

\section{Proporción de profesorado contratado}

La LOU estableció (Art. 48.1) que el número total del personal docente e investigador (PDI) contratado no podría superar el $49 \%$ del total del PDI de la universidad, con la indicación de que los profesores asociados con plazas vinculadas sanitarias serían excluidos del cómputo (D.A. 12. ${ }^{\mathrm{a}}$ ). Pero no especificó si debía realizarse un cómputo simple (suma total del personal sin te- ner en cuenta su dedicación) o ponderado (suma del profesorado considerando su dedicación a tiempo completo o parcial), lo cual generó una situación ambigua y potencialmente conflictiva [9]. El conflicto surgió cuando, contrariamente a la interpretación que hacía el Gobierno, algunas normas universitarias autonómicas -las de Cataluña [10] (Art. 29.3), Andalucía [11] (Art. 34), País Vasco [12] (Art. 15.1), Baleares [13] (Art. 2.3) y Extremadura [14] (Art. 177)- optaron por la segunda alternativa al prever un cómputo del PDI 'en equivalencias a tiempo completo'. Como respuesta, el Gobierno del PP interpuso recurso de inconstitucionalidad contra ésta y algunas otras disposiciones de la Ley de Universidades de Cataluña en mayo de 2003 y el ulterior Gobierno del PSOE lo hizo contra la Ley del Sistema Universitario Vasco en junio de 2004. El Tribunal Constitucional (TC) admitió a trámite ambos recursos y determinó la suspensión cautelar del articulado recurrido [15-18].

La ambigüedad existente en la LOU desapareció en el primer borrador del anteproyecto de ley de modificación de la LOU elaborado por el MEC [3], el cual mantuvo el $49 \%$ como porcentaje máximo que el PDI contratado podía suponer del PDI de las universidades públicas, y precisó que dicho cómputo debía establecerse en equivalencias a tiempo completo. En la fase de tramitación del proyecto de ley en el Congreso de los Diputados se presentaron dos enmiendas: una del Grupo Parlamentario Vasco en el sentido de incrementar hasta el 55\% dicho porcentaje, y otra de Izquierda Unida-Iniciativa por Catalunya Verds (IU-ICV), precisando que las figuras de personal académico contratado temporal no podrían superar el $40 \%$ de la plantilla docente [19]. Ambas enmiendas fueron rechazadas, pero la Comisión de Educación y Ciencia del Senado introdujo una enmienda que recogía la restricción propuesta por IU-ICV [20]. Por otra parte, la LOMLOU (D.A. 12. ${ }^{a}$ ) mantuvo la exclusión de los profesores asociados con plazas vinculadas sanitarias al establecer el cómputo, existente ya en la LOU, a la vez que, incorporando una enmienda presentada por el Grupo Parlamentario Vasco que recogía una disposición de la Ley del Sistema Universitario Vasco que había sido objeto de recurso, también excluyó a quienes no impartieran docencia en las enseñanzas conducentes a la obtención de títulos oficiales, así como al personal propio de los institutos de in- 
vestigación adscritos a la universidad (Art. 48.4). La nueva redacción de la disposición referente al cómputo del PDI hacía desaparecer una de las causas de recusación de las leyes universitarias catalana y vasca. Por ello, y por razones de tipo político, el Gobierno trasladó la decisión de desistimiento de los recursos al TC, que en febrero de 2007 emitió un auto declarando extinguidos los correspondientes procesos y archivando las actuaciones [21,22].

\section{Figuras de profesor contratado permanente}

La LOU (Art. 48) había determinado que las comunidades autónomas, en los términos de la ley y en el marco de sus competencias, establecerían el régimen del PDI contratado de las universidades. Y había precisado que éstas podrían contratar, en régimen laboral, PDI entre las figuras de ayudante, profesor ayudante doctor, profesor colaborador, profesor contratado doctor, profesor asociado y profesor visitante, de las cuales sólo las figuras de profesor contratado doctor (PCD) y de profesor colaborador (PC) podrían ser contratadas con carácter permanente.

La normativa sobre el régimen del PCD establecida por las diversas comunidades autónomas en desarrollo de la LOU presentaba diferencias significativas [9]. Por lo que respecta al tipo de contrato, la mayoría de comunidades habían optado por el contrato de duración indefinida, si bien algunas permitían que el contrato pudiera ser también temporal, o habían derivado la decisión a las propias universidades. También había diferencias en cuanto al régimen de dedicación (a tiempo completo o a tiempo parcial): unas comunidades habían establecido la dedicación a tiempo completo como régimen único o preferente, mientras que otras habían dejado abiertas las opciones. Pero las mayores diferencias se debían al hecho de que algunas normas autonómicas habían desdoblado la figura de PCD, en un remedo de los cuerpos de profesores funcionarios.

Castilla-La Mancha, Comunidad de Madrid, La Rioja y Comunidad Valenciana habían mantenido una normativa de carácter muy general. Castilla-La Mancha se había limitado a indicar que la contratación de PCD sería, con carácter general, por tiempo indefinido y con régimen de dedicación a tiempo completo [23] (Art. 8). La Comunidad de Madrid [24] (Arts.12 y 13) y la Comunidad Valenciana [25] (Art. 6) habían establecido que los contratos de PCD serían por tiempo indefinido, preferentemente con dedicación a tiempo completo. Y la normativa de La Rioja había determinado que el PCD podría ser contratado por tiempo indefinido o con carácter temporal, preferentemente en régimen de dedicación a tiempo completo [26] (Art. 7).

Habían establecido dos categorías de PCD las normativas de Andalucía, Aragón, Cataluña, Extremadura, Canarias, Murcia y País Vasco.

En Andalucía, la Ley Andaluza de Universidades había distinguido dos modalidades de contratación de PCD: la ordinaria y la extraordinaria. La modalidad ordinaria se aplicaría para desarrollar tareas de docencia e investigación, o prioritariamente de investigación. La contratación sería a tiempo completo y por una duración inicial de cinco años; superada una evaluación positiva de la actividad desempeñada por la Agencia Andaluza de Evaluación de la Calidad y Acreditación Universitaria, el contrato pasaría a tener carácter indefinido. La modalidad de contratación extraordinaria se aplicaría para desarrollar actividades de docencia e investigación de naturaleza singular o especializada; podría tener una duración máxima de cinco años [11] (Arts. 38 y 40).

En Aragón, la normativa había determinado que la contratación del PCD, preferentemente en régimen de dedicación a tiempo completo, podría ser con carácter temporal o por tiempo indefinido (con posible concertación de un periodo de prueba que no podría exceder de seis meses), y había establecido la categoría de PCD extraordinario para desarrollar actividades investigadoras de excelencia o de docencia de alta especialización [27] (Arts. 7 y 28).

En Extremadura se había establecido la existencia de PCD tipo I y tipo II. El tipo I, destinado a funciones docentes e investigadoras, sería el inicial. El acceso al tipo II, que conllevaría una mayor dedicación investigadora (con obligación de dirigir proyectos y grupos de investigación), supondría la existencia de vínculo previo contractual del tipo I durante, al menos, dos años y evaluación externa positiva. En ambos casos, la contratación sería por tiempo indefinido, con régimen de dedicación a tiempo completo o a tiempo parcial según las necesidades de la universidad [28] (Art. 6). 
En Canarias se habían distinguido dos tipos de PCD en base a las funciones a desarrollar: el tipo 1 , que desarrollaría tareas docentes e investigadoras, y el tipo 2, cuyas funciones serían preferentemente investigadoras (con obligación de dirigir proyectos y grupos de investigación y de someter a evaluación externa cada seis años los resultados obtenidos). Sólo los profesores tipo 1, con dedicación a tiempo completo, podrían ser contratados con carácter indefinido [29] (Art. 4).

La normativa de la Región de Murcia había determinado que la contratación del PCD sería, con carácter general, con dedicación a tiempo completo, y excepcionalmente a tiempo parcial hasta un máximo de cuatro años, y que las universidades regularían las condiciones de paso a la contratación definitiva previo informe favorable de un órgano de evaluación externa. Diferenciaba un tipo de PCD con 'funciones docentes e investigadoras' y otro tipo con 'funciones docentes y de dirección de investigación’ [30] (Art. 17).

En Cataluña, la Ley de Universidades (LUC) había determinado que los contratos de PCD tendrían carácter permanente y había establecido dos categorías dentro de esta figura: el profesor agregado, con probada capacidad docente e investigadora, y el catedrático contratado, con carrera docente e investigadora consolidada [10] (Art. 46). El artículo que establecía la figura de catedrático contratado fue uno de los recurridos ante el TC por el Gobierno del PP, por considerar que la denominación de catedrático debía quedar reservada al cuerpo de funcionarios del Estado. El tribunal suspendió cautelarmente dicho artículo, pero unos meses más tarde levantó dicha suspensión $[15,16]$. Por lo que respecta al régimen de dedicación, la LUC había dejado libre la opción entre dedicación a tiempo completo y a tiempo parcial.

En el País Vasco, la Ley del Sistema Universitario había establecido dos categorías de PCD: el profesorado agregado, para el acceso al cual se requería acreditar como mínimo tres años de actividad docente universitaria e investigadora, y el profesorado pleno, para cuyo acceso se requería tener la condición de profesor agregado y acreditar como mínimo tres años de actividad docente universitaria e investigadora, o pertenecer a cualquiera de los cuerpos docentes universitarios que exigen el título de doctor. Ambas categorías se contratarían con régimen de dedicación a tiempo completo [12] (Arts. 19 y 20).
La normativa gallega había derivado la regulación del régimen del PCD a las propias universidades. Había especificado que los PCD podrían desarrollar sus tareas con dedicación a tiempo completo o a tiempo parcial, pudiendo los primeros ser contratados con carácter permanente [23] (Art. 7). No había establecido directamente la existencia de dos categorías de PCD, pero indirectamente reconocía esta posibilidad al fijar un abanico salarial que iba desde 'un mínimo como profesor titular de universidad a un máximo como catedrático de universidad' [31] (Art. 15).

Castilla-León había establecido tres tipos de PCD (básico, permanente y senior), en función de la experiencia posdoctoral acreditada: tres, seis y doce años de actividad docente e investigadora o prioritariamente investigadora, como mínimo, respectivamente. Los contratos de PCD permanente y de PCD senior tendrían carácter fijo y se realizarían con régimen de dedicación a tiempo completo [32] (Art. 19).

Las Islas Baleares habían determinado que el régimen de dedicación del PCD sería a tiempo completo, con posibilidad de contrato indefinido o temporal [13] (Art. 6). La normativa indicaba que la figura de PCD podría desarrollarse con la creación de diversas categorías de profesorado en función de las necesidades docentes e investigadoras de la universidad [13] (D.A. 4. ${ }^{\text {a) }}$.

El primer borrador del proyecto de ley de modificación de la LOU [3] mantenía dentro del profesorado universitario contratado las figuras de ayudante, profesor ayudante doctor, profesor asociado y profesor visitante. Eliminaba las figuras de PCD y de profesor colaborador, si bien indicaba que, en el marco de la regulación que dictasen las comunidades autónomas, las universidades podrían contratar otro personal docente e investigador con carácter permanente o temporal cuya denominación no podría ser ninguna de las utilizadas por esta ley.

La CRUE [33], la Plataforma Estatal de Profesores Contratados [34] y el SIPU [35] se manifestaron en el sentido de que la ley debía garantizar que la figura de PCD permanente continuara existiendo en todo el sistema universitario, por lo que el segundo borrador ministerial [4] recuperó la figura de PCD; precisó que su contrato sería de carácter indefinido y con dedicación a tiempo completo, y suprimió el requisito establecido por la LOU de que los candidatos tuvieran 
que acreditar tres años de actividad docente e investigadora.

Por otra parte, la CRUE [33], la Agencia Nacional de Evaluación de la Calidad y Acreditación (ANECA) [36] y la FETE-UGT [37] señalaron el riesgo de que, al dejar en manos de las comunidades autónomas la legislación sobre el profesorado contratado, se produjera una excesiva y posiblemente conflictiva proliferación de figuras contractuales diversas, y la CRUE [33] insistió en que debería garantizarse que dichas comunidades no regularían contratos permanentes para profesores no doctores. Esta posibilidad se mantuvo en el segundo borrador del proyecto de ley [4], pero quedó excluida en el anteproyecto de la ley aprobado por el Consejo de Ministros [5], y si bien en la fase de tramitación en el Congreso un parlamentario del Grupo Mixto presentó una enmienda para recuperarla [19], fue rechazada.

La CRUE indicó, también, la necesidad de aclarar si las plazas de PCD permanente podían vincularse a plazas asistenciales de las instituciones sanitarias, posibilidad que se incorporó a la modificación de la Ley General de Sanidad incluida en la versión del anteproyecto de ley aprobado finalmente por el Consejo de Ministros [5].

Durante la tramitación parlamentaria, las disposiciones relativas al PCD no sufrieron ninguna modificación, si bien una disposición adicional (D.A. 3. ${ }^{\mathrm{a}}$ ) determinó que los profesores colaboradores que estuvieran contratados con carácter indefinido, poseyeran el título de doctor o lo obtuvieran tras la entrada en vigor de la Ley y consiguieran una evaluación positiva, accederían directamente a la categoría de PCD en sus propias plazas. Por otra parte, una disposición transitoria (D.T. 2. ${ }^{a}$ ) estableció que el Gobierno reglamentaría las condiciones y plazos en los que, de forma excepcional, las universidades podrían contratar profesores colaboradores entre diplomados, arquitectos técnicos o ingenieros técnicos. El año 2008 se publicó la legislación que desarrollaba dicha disposición [38,39].

Como resultado de la promulgación de la LOMLOU, la normativa universitaria de las comunidades autónomas sobre el PCD ha debido adaptarse a las modificaciones introducidas por la ley y se ha eliminado la posibilidad de contratación temporal y de régimen de dedicación a tiempo parcial $[40,41]$.

\section{Acreditación previa a la contratación}

Por lo que respecta a los requisitos necesarios para la contratación como PCD, la LOU (Art. 52) había dispuesto la previa evaluación positiva por la ANECA o por los órganos de evaluación que la Ley de las Comunidades Autónomas determinase en el ámbito de sus respectivas competencias. En desarrollo de esta disposición, en octubre del año 2002 se publicó el Real Decreto que estableció el procedimiento a seguir para la obtención de la evaluación por la ANECA [42]; pocos días después se dio a conocer la resolución por la que se establecían los criterios generales de evaluación de la ANECA y el procedimiento de presentación de solicitudes [43], y en junio de 2003 se publicó otra resolución por la que se establecía el procedimiento de solicitud de evaluación de la ANECA para la contratación de personal docente e investigador en los supuestos de solicitantes pertenecientes a cuerpos docentes universitarios o que se encontrasen habilitados de acuerdo con la LOU, y se especificaban los criterios de evaluación a estos efectos [44].

Entre tanto, el Gobierno de la Generalitat de Catalunya había formulado un requerimiento de incompetencia al Gobierno de la nación [45] para que modificara algunos artículos del Real Decreto de 2002 por estimar que, al extender los efectos del procedimiento, certificado e informes objeto de regulación a todas las universidades españolas, vulneraban sus competencias en materia de enseñanza. Y, vista su respuesta negativa, en mayo de 2003 había presentado conflicto positivo de competencia que fue aceptado por el Tribunal Constitucional [46] y que todavía no se ha resuelto.

Como hemos comentado en un artículo anterior [47], el Programa de Evaluación del Profesorado para la contratación (PEP) de la ANECA, iniciado a finales del año 2002, recibió críticas muy numerosas y de muy diverso origen ${ }^{1}$. Hecho al que, como reconoció la propia agencia $[48,49]$, contribuyeron diversos factores, entre ellos el elevado volumen de solicitudes de evaluación presentadas que desbordó ampliamente

\footnotetext{
1 Especialmente crítico fue el análisis del proceso de evaluación realizado por el catedrático de Derecho Procesal de la Universidad Complutense, Andrés de la Oliva [99-102], quien publicó un manifiesto [103] que recibió centenares de adhesiones [104].
} 
las expectativas, la asimetría en las figuras solicitadas y las esperadas, la ausencia inicial de criterios definidos y de herramientas para la evaluación, la falta de referentes publicados que definiesen los niveles que se estaban aplicando, la novedad que suponía para las universidades la evaluación externa de sus contratados, la 'resistencia' desde ciertos sectores universitarios y la existencia de 'dificultades' en la comunicación con los interesados.

Por todo ello, con la llegada de un nuevo equipo gestor a la ANECA consecutiva al acceso del PSOE al Gobierno, en el año 2004 se planteó una revisión a fondo del PEP con el objeto de superar sus debilidades. Por parte de los nuevos responsables, y con la colaboración de un grupo de expertos externos, se realizó una metaevaluación del programa que condujo, en febrero del año 2005 [49-51], al establecimiento de un nuevo modelo de evaluación más ágil, sencillo y transparente. Se fijaron unos criterios de evaluación que, manteniendo una troncalidad común para todas las áreas de conocimiento y figuras contractuales de acuerdo con criterios cuantificables, permitían la introducción de especificidades concretas para grupos de áreas de conocimiento afines, de forma que se adaptasen a la realidad docente e investigadora de la universidad española. Se determinó que la motivación de los resultados negativos debía hacerse de forma que proporcionara a los candidatos información relevante sobre la calidad de su currículo. Se estableció la convalidación de las evaluaciones de diferentes figuras contractuales y se determinaron las figuras contractuales para las cuales los profesores pertenecientes a cuerpos docentes universitarios o habilitados para los mismos estarían cualificados automáticamente sin necesidad de solicitar evaluación.

Los criterios de evaluación se estructuraron en cuatro bloques de méritos (experiencia investigadora, experiencia docente, formación académica y experiencia profesional, y otros méritos), con distintos pesos relativos para cada figura contractual. Para la figura de PCD, las puntuaciones máximas para los cuatro bloques sobre un total de 100 puntos serían $60,30,8(6 / 2)$ y 2 puntos, respectivamente. Para obtener acreditación deberían cumplirse simultáneamente dos condiciones: alcanzar un mínimo de 50 puntos en la suma de los bloques de experiencia investigadora y experiencia docente, y conseguir un mínimo de 55 puntos en el total de los bloques. Por lo que se refiere a los méritos concretos incluidos en cada bloque, se mantuvieron esencialmente los mismos del procedimiento de evaluación original. En el bloque de la experiencia docente, se incluyeron cuatro tipos de méritos: a) amplitud, intensidad, grado de responsabilidad, ciclos y tipo de docencia en el ámbito disciplinar; b) evaluaciones sobre la calidad de la docencia; c) actuación como ponente en seminarios y cursos, y participación en congresos específicamente orientados a la formación para la docencia universitaria; y d) elaboración de material docente y publicaciones relacionadas con la docencia, participación en proyectos de innovación docente competitivos, y participación en planes y equipos de trabajo relacionados con el Espacio Europeo de Educación Superior (EEES). La puntuación máxima en cada uno de los grupos de méritos docentes sería, respectivamente, 17, 3, 3 y 7 puntos [50]. Los correspondientes baremos, perfectamente detallados para permitir que los interesados pudieran autoevaluarse, se hicieron públicos en las páginas web de la Dirección General de Universidades y de la ANECA [52], a las cuales se incorporó también una 'Guía de ayuda al solicitante' [53]. Finalmente, en abril de 2005 se estableció un procedimiento mixto de selección de los miembros de los diversos comités de evaluación del PEP por méritos de calidad y sorteo, con formación en el modelo previa a su incorporación [54].

Desde noviembre de 2002, en que se puso en marcha el PEP, hasta junio de 2005, en que se hicieron efectivas las modificaciones descritas, en la ANECA se habían evaluado 5.637 solicitudes de PCD, un $61 \%$ de las cuales recibió evaluación positiva. Un $43 \%$ de las solicitudes que habían tenido evaluación negativa presentó recurso, obteniendo evaluación final positiva un $25 \%$ de ellas, con lo cual el total de solicitudes que alcanzaron evaluación positiva había sido del $63 \%$. Por lo que respecta al ámbito de ciencias de la salud, se presentaron 803 solicitudes de evaluación de PCD. Fueron evaluadas positivamente en primera instancia un $45 \%$; presentó recurso un $46 \%$ de los solicitantes con evaluación negativa, y obtuvo evaluación positiva un 36\% de los recursos presentados, con lo cual el porcentaje final de evaluaciones positivas llegó al 52\% [55].

Durante el primer año de vigencia del nuevo modelo de evaluación (junio de 2005 a mayo 
2006), la ANECA evaluó 1.334 solicitudes de PCD, 149 de ellas del ámbito de ciencias de la salud. Recibieron evaluación positiva en primera instancia un $67 \%$ y un $66 \%$, respectivamente, $y$ los porcentajes de recursos de las evaluaciones negativas fueron el $23 \%$ y el $18 \%$ [56].

Durante el año 2006 se evaluaron 8.292 solicitudes, 1.739 de ellas para PCD; pertenecientes al área de ciencias de la salud, 929 y 327, respectivamente. Recibieron evaluación positiva el $68 \%$ del total de solicitudes de esta área y el $65 \%$ de las solicitudes para PCD. El correspondiente informe de la ANECA resaltó que los recursos presentados representaron sólo el 19\% de las evaluaciones negativas, lo que supuso una importante disminución respecto al modelo anterior del PEP, y atribuyó este hecho al esfuerzo que los comités realizaron en la motivación personalizada del currículo de cada solicitante, orientándolo en acciones de mejora para su futura trayectoria profesional [48].

En el año 2007, publicada la LOMLOU, el PEP se adaptó a las modificaciones introducidas por la ley y a los 'Criterios y directrices para la garantía de calidad en el EEES' [57], y se publicaron en la web de ANECA versiones actualizadas de los documentos 'Principios y orientaciones para la aplicación de los criterios de evaluación' [58], 'Guía de ayuda al solicitante' [59], 'Respuestas a preguntas frecuentes' [60] y 'Procedimiento para la constitución y renovación de la Comisión y Comités de Evaluación del PEP [61]. A lo largo de este año, las solicitudes evaluadas fueron 7.510, de las cuales 2.198 fueron para PCD. De ellas, pertenecieron al área de ciencias de la salud 440 y 117, respectivamente. Recibieron evaluación positiva, en primera instancia, el $63 \%$ del total de solicitudes de esta área y el 59\% de las solicitudes para PCD [62].

Durante el año 2008 fueron evaluadas por la ANECA 5.707 solicitudes, 2.276 de ellas para PCD, pertenecientes al área de ciencias de la salud 710 y 141, respectivamente. Recibieron evaluación positiva, en primera evaluación, el 59\% del total de solicitudes de esta área y el 52\% de las solicitudes para PCD [63].

La mayoría de las agencias de las comunidades autónomas que, de acuerdo con lo dispuesto por la LOU, iniciaron el proceso de evaluación de los aspirantes a contratos de PCD, agruparon los méritos a avaluar en bloques semejantes a los establecidos por la ANECA, si bien difirieron algo en el peso relativo que otorgaron a cada uno de ellos.

La Agencia de Calidad Universitaria de Castilla-La Mancha acordó realizar la evaluación utilizando los mismos criterios y baremos que la ANECA [64].

La Agencia Andaluza de Evaluación modificó algo los baremos de la agencia estatal: disminuyó el peso de la experiencia investigadora (de un $60 \%$ a un 50\%) y aumentó el peso de la experiencia docente (de un $30 \%$ a un $40 \%$ ). Estableció que para obtener la acreditación hacía falta alcanzar un mínimo de 55 puntos en la suma de todos los bloques y un mínimo de 50 puntos en la suma de los bloques 'experiencia investigadora $y$ de transferencia de conocimiento' y 'experiencia docente', con un mínimo de 20 y 15 puntos, respectivamente, en cada bloque [65].

La Agencia de Calidad del Sistema Universitario de Castilla y León, respecto de la ANECA, redujo el peso relativo de la experiencia investigadora a un $40 \%$, mantuvo el peso de la experiencia docente en un 30\% y aumentó hasta un $15 \%$ el peso de la formación académica y de la experiencia profesional y otros méritos. Determinó que la evaluación positiva requería un mínimo de 60 puntos totales, 20 puntos de experiencia investigadora y 10 puntos de experiencia docente, si bien éstos podían reducirse a 6 cuando la puntuación en experiencia investigadora llegara a 35 puntos [66].

La Axencia para a Calidade do Sistema Universitario de Galicia, en comparación con la agencia estatal, disminuyó tanto el peso de la experiencia investigadora (35\%) como el de la experiencia docente $(20 \%)$; valoró separadamente la experiencia de gestión (10\%) e incrementó el peso relativo de los meritos profesionales (15\%), de la formación académica (15\%) y de los otros méritos (5\%). Agrupó los méritos de actividad docente en tres apartados (amplitud, intensidad y tipo de docencia impartida, formación didáctica, y otros méritos docentes), y determinó que para lograr evaluación positiva se requería obtener un mínimo de 45 puntos en la suma de todos los bloques, 15 puntos en actividad investigadora y 10 puntos en actividad docente [67-69].

La Agencia de Qualitat Universitaria de les Illes Balears estableció los mismos bloques de méritos que la ANECA, si bien dividió en dos el bloque 'formación académica y experiencia profesional'. Dentro del bloque 'experiencia docente', esta- 
bleció como criterios la amplitud y experiencia docente, las instituciones y los centros donde se ha ejercido la docencia, las evaluaciones de la calidad docente, la formación didáctica, la participación en proyectos de innovación didáctica, la elaboración de material docente y otros méritos [70]. No nos consta que se hayan publicado los baremos y las correspondientes puntuaciones de los diversos méritos.

Como ya se ha comentado, el Gobierno de Canarias estableció la existencia de dos tipos de PCD: el tipo 1, que desarrolla tareas docentes y de investigación, y el tipo 2, cuyas funciones son preferentemente investigadoras. Y de acuerdo con ello, la Agencia Canaria de Evaluación de la Calidad y Acreditación Universitaria fijó criterios diferenciados para la evaluación de los aspirantes a ambos tipos de contrato. Para los profesores tipo 1, respecto de la ANECA, mantuvo el peso de la docencia (formación para la docencia, experiencia docente y otros méritos) en un $30 \%$, disminuyó el peso de la actividad investigadora a un $45 \%$, acordó ponderar separadamente la formación académica con un 15\% e incluyó la experiencia profesional en el bloque de otros méritos (10\%). Para los profesores tipo 2, incrementó hasta un $70 \%$ el peso de la actividad investigadora y acordó ponderar con un $10 \%$ la suma de la experiencia docente y la experiencia profesional, con un $10 \%$ la formación académica y con otro $10 \%$ el bloque de otros méritos. Para esta agencia, para obtener una evaluación positiva como PCD tipo 1, hace falta alcanzar un mínimo de 10 puntos de actividad investigadora y 12 puntos de actividad docente, y para hacerlo como PCD tipo 2, deben alcanzarse como mínimo 25 puntos de actividad investigadora [71,72].

Agruparon los méritos objeto de evaluación de acuerdo con criterios algo distintos a los anteriores las agencias madrileña, valenciana y vasca.

La Agencia de Calidad, Acreditación y Prospectiva de las Universidades de Madrid considera cuatro criterios de méritos: 'experiencia (docente, investigadora y profesional)', 'producción académica y científica y su difusión', 'formación (académica y complementaria)' y 'otros méritos'. Según el cómputo aplicado en la convocatoria del año 2008, distinto del aplicado en convocatorias anteriores, las máximas puntuaciones directas que puede alcanzar en estos cuatro criterios son: 45, 20, 15 (6 para el subcriterio 'formación académica' y 9 para el subcriterio 'formación comple- mentaria') y 15 , respectivamente. Las puntuaciones directas, escaladas en base 100, reciben para el PCD los pesos relativos de $40 \%, 40 \%, 15 \%$ y $5 \%$, y para recibir evaluación positiva deben obtenerse un mínimo de 65 puntos [73,74].

En la Comunidad Valenciana, el proceso de evaluación para la contratación del profesorado universitario inicialmente corría a cargo de la Comissió Valenciana d'Acreditació i Avaluació de la Qualitat en el Sistema Universitari Valencià, la cual distribuía los méritos objeto de evaluación en los apartados 'formación integral', 'actividad docente', 'actividad investigadora' y 'actividad profesional', y otorgaba un peso del $30 \%$ al segundo bloque, del $50 \%$ al tercer bloque y del $20 \%$ a la suma de los bloques primero y cuarto [75]. Sin embargo, creada l'Agència Valenciana d'Avaluació i Prospectiva el año 2006, pasó a ser ésta la encargada de dicha evaluación. De acuerdo con la convocatoria del año 2008, dicha agencia utilizó como criterios de evaluación, con la ponderación que se indica en paréntesis para el PCD: 'formación académica y experiencia profesional' (10\%), 'experiencia investigadora y de transferencia de conocimiento' (55\%), 'experiencia docente' (30\%) y 'otros méritos' (5\%). Para obtener acreditación para PCD hacía falta alcanzar un mínimo de 20 puntos en el segundo apartado, 15 puntos en el tercero y 55 puntos en la suma de todos los apartados [76].

En Cataluña, la LUC estableció que para ser admitido en los procesos selectivos convocados por las universidades para acceder a plazas de PCD era necesario obtener una acreditación de investigación o de investigación avanzada, según se tratara de una plaza de profesor agregado o de catedrático, respectivamente, y un informe de la actividad docente desarrollada, si así lo exigían las universidades en las convocatorias. Ambos, acreditación e informe, serían emitidos por la Agència para la Qualitat del Sistema Universitari de Catalunya (AQU Catalunya) [10] (Art. 47.1), si bien las evaluaciones y las acreditaciones hechas por otras agencias u órganos de evaluación 'podían ser consideradas' por dicha agencia [10] (Art. 148.2). Estas disposiciones fueron recurridas mediante el recurso de inconstitucionalidad que, como se ha mencionado antes, interpuso el Gobierno del PP el año 2003 [15]. El TC determinó inicialmente la suspensión cautelar de los correspondientes artículos y, si bien a los cuatro meses levantó la suspensión del art. 47.1, mantu- 
vo suspendido el art. 148.2 por entender que su aplicación efectiva, al determinar que las acreditaciones de la ANECA no producirían efectos automáticos en Cataluña, podría suponer perjuicios irreparables o de difícil reparación para el profesorado acreditado por dicha agencia [16]. Producido el desistimiento del recurso [21] y hasta que el TC no resuelva el conflicto positivo de competencia presentado por el Gobierno de la Generalitat de Catalunya [46], las universidades catalanas han aceptado tanto el informe de acreditación emitido por la ANECA como el emitido por la AQU.

En el artículo antes mencionado [47] se detallaban los procesos desarrollados inicialmente por la agencia catalana para acreditar la capacidad investigadora y para certificar o evaluar la actividad docente. Cabe comentar ahora que, en enero de 2005, dicha agencia modificó los criterios que venía utilizando para acreditar la investigación, equiparando la transferencia de resultados con las publicaciones. Pasó así a evaluar cuatro apartados de méritos ('publicaciones y transferencia de resultados de la investigación', 'proyectos', 'actividad formativa' y 'otros méritos') con una ponderación relativa, en el ámbito de ciencias médicas y de la salud, del 70\%, 15\%, $10 \%$ y $5 \%$, respectivamente $[77,78]$. Para la emisión de la certificación de la actividad docente, AQU Catalunya valora preferentemente el autoinforme del profesor, el encargo de actividad docente, el desarrollo y la actuación profesional, y la satisfacción de los estudiantes y graduados $[79,80]$. Cabe señalar que durante el período 2003-2008 esta agencia evaluó 2.495 solicitudes para acreditación de investigación y 813 solicitudes para acreditación de investigación avanzada, de las cuales 652 y 244 , respectivamente, pertenecían al ámbito de ciencias médicas y de la salud. Recibieron evaluación positiva el $46 \%$ y el 57\% del total de solicitudes evaluadas, y el $43 \%$ y el $49 \%$ de las solicitudes del ámbito de ciencias médicas y de la salud, respectivamente [81-83]. En cambio, durante el período 2004-2007 sólo hubo 164 solicitudes de certificación de la actividad docente, de las cuales sólo se desestimó un 1,2\% [84]. Recientemente, la AQU, con el fin de conocer el grado de satisfacción de las personas evaluadas respecto al proceso de evaluación, dirigió una encuesta a todos los solicitantes que habían participado en la primera convocatoria del año 2008, entre ellos 295 solicitantes de acreditación de investigación o de investigación avanzada, de los cuales contestaron casi la mitad (un $57,4 \%$ de ellos con evaluación positiva y un $42,6 \%$ con evaluación negativa). Algo más de la mitad de esta población manifestó haber contactado con la agencia para solicitar información y un $94 \%$ valoró como muy positivo o como positivo el trato recibido. Por lo que se refiere al proceso de evaluación, en una escala de 1 a 5 , recibió una puntuación de 2,8 la composición de las comisiones de evaluación, de 2,83 la claridad informativa de los criterios de evaluación, de 3,0 la adecuación de las evidencias solicitadas y de los elementos que las identifican, y de 3,97 los requisitos mínimos exigidos para poder presentarse. Un aspecto esencial del proceso, el nivel de exigencia de los criterios de evaluación y la adecuación de los méritos asociados a cada criterio, recibió una puntuación relativamente alta $(2,95)$. En cambio, recibió una mala valoración la argumentación emitida en caso de evaluación negativa, la cual fue considerada poco clara por un $55,1 \%$ de los encuestados [85].

En el País Vasco se produjo una situación de conflicto competencial semejante a la que se había dado en Cataluña, dado que en diversos artículos de la Ley del Sistema Universitario Vasco relativos al profesorado contratado se determinaba como requisito para la contratación disponer de evaluación positiva de la actividad docente e investigadora acreditada con el informe de la Agencia de Evaluación de la Calidad y Acreditación del Sistema Universitario Vasco u organismo similar reconocido por la normativa vasca [10] (Arts. 20-23, D.T. 1.a y 2.a ). El Gobierno del PSOE presentó recurso de inconstitucionalidad, en respuesta al cual el TC determinó la suspensión cautelar de los artículos recurridos $[16,18]$, que se mantuvo hasta que se produjo el desistimiento del recurso [22].

La agencia vasca estableció los criterios de evaluación para las diversas categorías de profesorado contratado, que por lo que se refiere al PCD (profesorado pleno y profesorado agregado) en la convocatoria del año 2008 , fueron los siguientes, con la ponderación indicada entre paréntesis: 'actividad investigadora y transferencia de conocimiento' (55 puntos), 'actividad docente y experiencia profesional' (35 puntos), 'gestión y administración' ( 5 puntos), 'formación académica adicional' (5 puntos) y 'actividades a favor de la normalización del uso del euskera 
en el ámbito universitario' (10 puntos). Dentro del apartado de 'actividad docente' se incluyeron tres subapartados: 'trayectoria docente universitaria' (hasta 25 puntos), 'publicaciones docentes' (hasta 10 puntos) e 'innovación docente y otros méritos docentes' (hasta 10 puntos). Para conseguir la acreditación como profesor pleno se requería obtener, como mínimo, 80 puntos totales, 45 puntos en el apartado primero y 25 puntos en el segundo. Para ser acreditado como profesor agregado, los mínimos necesarios eran: 65 puntos totales, 30 puntos en el apartado primero y 20 puntos en el segundo [86-88].

La Agencia de Calidad y Prospectiva Universitaria de Aragón no realiza el proceso de evaluación del profesorado cuando redactamos este artículo [89].

Cabe destacar que si bien inicialmente las agencias autonómicas realizaron las evaluaciones del profesorado independientemente una de la otra, ya en abril del año 2005 la ANECA y siete agencias autonómicas de evaluación de la calidad se reunieron con el fin de avanzar en la armonización de las metodologías y procesos de evaluación, y manifestaron su voluntad de alcanzar el reconocimiento mutuo de los resultados de sus evaluaciones [90,91]. Al año siguiente, la ANECA y las agencias de Andalucía, Castilla-La Mancha, Castilla y León, Cataluña, Galicia, Islas Baleares, Canarias, Comunidad de Madrid y País Vasco constituyeron la Red Española de Agencias de Calidad Universitaria (REACU), con el fin de promover su colaboración y contribuir a crear las condiciones para el mutuo reconocimiento de sus decisiones [92,93]. En abril del año 2007 se adhirieron a la red las agencias de calidad de Aragón y Comunidad Valenciana [94].

Coincidiendo con la creación de la REACU, las agencias que constituyeron la red hicieron público un documento sobre 'Armonización de la evaluación del profesorado' [95], resultado de la labor a lo largo de diez meses de varios grupos de trabajo. En este documento se definió la figura de PCD como la 'correspondiente a aquellos doctores que acrediten una experiencia docente e investigadora posdoctoral consolidada'. Se concluyó que los requisitos mínimos a considerar para la acreditación de los aspirantes a un contrato de esta categoría abarcan dos grandes dimensiones imprescindibles y no compensables: la experiencia investigadora y la experiencia docente. Se verificó que, en mayor o en menor grado, todas las agencias utilizaban más criterios de valoración que los estrictamente necesarios y, por ello, se recomendó que llevaran a cabo un ejercicio de simplificación para facilitar la convergencia y el establecimiento de sistemas de reconocimiento mutuo. Por lo que respecta a la evaluación de la experiencia docente, el documento señaló que debía valorarse la amplitud, intensidad y tipología de la docencia en el correspondiente ámbito disciplinar en enseñanzas universitarias, fundamentalmente regladas, e indicó que debía valorarse especialmente la docencia con evaluación de su calidad, la participación en proyectos de innovación docente, la elaboración de material docente y las publicaciones relacionadas con la actividad docente. Por otra parte, el documento incluyó unas recomendaciones sobre el perfil idóneo de los evaluadores, los sistemas de selección de éstos y la estructura de los comités de acreditación.

Señalemos, finalmente, que el documento también analizó los resultados de las evaluaciones realizadas por la ANECA y las agencias autonómicas durante el periodo 2003-2005. Concluyó que la figura de PCD, junto con la de profesor de las universidades privadas, es la que presenta mayor grado de dispersión. En el campo de ciencias de la salud sólo las agencias valenciana y gallega se aproximan, quedando las agencias andaluza y canaria muy por encima (con un 100\% de resultados favorables) y la agencia castellanoleonesa muy por debajo de las demás. Los autores señalaron que la dispersión observada venía determinada, en parte, por las diferencias de los modelos utilizados y por el distinto tamaño de los universos objeto de evaluación.

\section{Concursos de acceso convocados por las universidades}

La regulación de los concursos de acceso a plazas de PCD convocados por las universidades se vio poco afectada por la promulgación de la LOMLOU. Prácticamente sólo hubo que modificar la normativa que se venía aplicando por lo que se refiere a las condiciones que debían reunir los candidatos, sin verse afectadas las normas de desarrollo de dichos concursos. Por ello, como comentamos en el caso de los concursos convocados durante la vigencia de la LOU [47], al comparar la normativa aplicada por las diversas 
Tabla. Profesorado permanente de las universidades españolas [98].

\begin{tabular}{|c|c|c|c|c|}
\hline & \multicolumn{4}{|c|}{ Curso } \\
\hline & $2004-2005$ & 2005-2006 & $2006-2007$ & $2007-2008$ \\
\hline \multicolumn{5}{|l|}{ Funcionario } \\
\hline CU & 8.875 & 8.786 & 8.659 & 9.075 \\
\hline TU & 28.371 & 28.202 & 28.069 & 28.509 \\
\hline CEU & 2.509 & 2.471 & 2.348 & 1.973 \\
\hline TEU & 12.238 & 12.108 & 11.839 & 11.480 \\
\hline \multicolumn{5}{|l|}{ Contratado } \\
\hline$P C D^{a}$ & 1.434 & 2.418 & 3.304 & 4.534 \\
\hline$P C^{a}$ & 1.348 & 2.038 & 3.387 & 4.240 \\
\hline A tiempo indefinido & 2.299 & 3.019 & 5.234 & 8.602 \\
\hline
\end{tabular}

CU: catedrático de universidad; TU: titular de universidad; CEU: catedrático de escuela universitaria; TEU: titular de escuela universitaria; PCD: profesor contratado doctor; PC: profesor colaborador. ${ }^{a}$ Incluye contratos temporales e indefinidos.

universidades con la entrada en vigencia de la LOMLOU se advierte que entre ellas hay el mismo tipo de diferencias existentes en el caso de los concursos de acceso a plazas de los cuerpos docentes, en cuanto al procedimiento seguido, al número de miembros de las comisiones, su procedencia y forma de designación ${ }^{2}$.

Respecto a la acreditación requerida para participar en los concursos, las universidades de comunidades autónomas que poseen agencia de evaluación propia generalmente especifican que admiten la acreditación emitida por dicha agencia y la emitida por la ANECA. Algunas universidades, entre las que se hallan la Universidad de Santiago de Compostela y la Complutense de Madrid, admiten también la acreditación emitida por agencias de otras comunidades con las que han establecido convenio o concierto de reconocimiento. Otras universidades, como la de Extremadura, la de Salamanca y la del País Vasco, indican que admiten la acreditación emitida por cualquier otro organismo legalmente reconocido. En Cataluña, en el curso 2007-2008, tenían

\footnotetext{
2 Las convocatorias de los concursos realizadas por las universidades pueden consultarse en las respectivas páginas web (generalmente, en el apartado 'PDI' o 'profesorado', 'concursos'), asequibles desde la web de la CRUE [105].
}

acreditación de investigación avanzada emitida por la AQU todos los profesores contratados por la universidades públicas a nivel de catedrático, $\mathrm{y}$ disponían de acreditación de investigación emitida por la agencia catalana el $88 \%$ de los contratados como profesores agregados [96].

\section{Consolidación de la vía laboral en la carrera del profesorado universitario}

Para acabar este análisis, queremos subrayar que, como resaltó el dictamen del Consejo de Estado sobre el proyecto de ley [6], la publicación de la LOMLOU supuso la consolidación de la figura de PCD como carrera laboral alternativa a la funcionarial. Con las modificaciones introducidas en la LOU, por una parte, se estableció que el contrato de los PCD sería 'de carácter indefinido y con dedicación a tiempo completo' (Art. 52 ), y por otra, se otorgaron a 'los profesores con vinculación permanente a la universidad' atribuciones que la LOU confería únicamente a 'los funcionarios doctores de los cuerpos docentes universitarios'. Entre ellas, la posesión de 'plena capacidad docente e investigadora' (Art. 52), el voto ponderado en la constitución del Claustro 
Universitario (Art. 16.3) y en la elección de rector (Art. 20.2), y la condición de elegibles para los órganos unipersonales de gobierno (salvo para el cargo de rector) (Arts. 24 y 25). Además, en el ámbito de las ciencias de la salud fue muy importante la modificación de la Ley General de Sanidad, determinando que podrá establecerse vinculación de determinadas plazas asistenciales no sólo con plazas de los cuerpos docentes de los cuerpos de profesores de universidad, sino también con plazas de PCD (D.F. 2).

Es difícil predecir cuánto tiempo tardará en consolidarse la vía laboral como alternativa a la vía funcionarial en la carrera del profesorado universitario, pero puede preverse que el ritmo y el grado con que ello tendrá lugar variarán de una comunidad autónoma a otra. En Cataluña, en el año 2003, la Generalitat puso en marcha el denominado 'Plan Serra Hunter' que preveía la incorporación a las universidades públicas catalanas de 1.200 PCD (400 catedráticos y 800 profesores agregados) en los próximos 12 años, para facilitar la constitución de un cuerpo docente propio paralelo al cuerpo funcionarial dependiente del Estado, como un importante paso para cubrir déficits estructurales, impulsar ámbitos de especial interés, dinamizar áreas emergentes y asegurar un relevo generacional [97].

La tabla, que recoge la distribución del profesorado funcionario y del profesorado contratado de todas las universidades públicas españolas durante los últimos cuatro cursos [98], muestra un incremento progresivo del porcentaje de profesorado con contrato indefinido, si bien, al no indicar cuántos PCD y cuántos PC poseen este tipo de contrato, no permiten apreciar la magnitud del incremento experimentado por el profesorado con contrato indefinido en cada uno de los dos grupos.

\section{Bibliografía}

Todas las web, excepto la de la referencia 84 (consultada con fecha 3 de junio de 2009), han sido confirmadas con fecha 9 de abril de 2009.

1. Carreras J. Evaluación de la calidad docente y promoción del profesorado (VI). Legislación universitaria española (d): modificación de la Ley Orgánica de Universidades. Profesorado funcionario: de la habilitación a la acreditación (2004-2008) (1. a parte). Educ Med 2009; 12: 63-72.

2. Ley Orgánica 6/2001, de 21 de diciembre, de Universidades (B.O.E. de 24-XII-2001), p. 49400-25.

3. MEC. Borrador de la Ley Orgánica de Modificación de la Ley Orgánica 6/2001, de 21 de diciembre, de Universidades (27-X-2005). URL: http://www.crue.org/boletines/boletin_n1/Adjuntos\%20de\%20AG\%2027-10-05/ Borrador_Lou.pdf.

4. MEC. Borrador del Anteproyecto de Ley Orgánica por la que se modifica la Ley Orgánica 6/2001, de 21 de diciembre, de Universidades (25-V-2006). URL: http:// www.crue.org/boletines/boletin_n7/boletin\%20n7\%20/ adjuntos/Anteproyecto\%20de\%20reforma\%20de\%20 la\%20LO (25-05-06).pdf.

5. MEC. Anteproyecto de Ley Orgánica por la que se modifica la Ley orgánica 6/2001, de 21 de diciembre, de Universidades (30-VI-2006). URL: http://www.crue.org/ boletines/boletin_n8/boletin $\% 20 n^{\circ} 8 /$ adjuntos/Aprobacion\%20LOU/Anteproyecto\%20LOU\%20consejo\%20 de\%20ministros\%20 30-6-06.pdf.

6. Consejo de Estado. Dictamen sobre el Anteproyecto de Ley Orgánica por la que se modifica la Ley Orgánica, de 21 de diciembre, de Universidades (19-VII-2006). Documento fotocopiado.

7. Proyecto de Ley 121/000101 Orgánica por la que se modifica la Ley Orgánica 6/2001, de 21 de diciembre, de Universidades. Boletín Oficial de las Cortes Generales. Congreso de los Diputados. VIII Legislatura, Serie A, n. ${ }^{\circ}$ 101 (8-IX-2006), p. 1-16.

8. Ley Orgánica 4/2007, de 12 de abril, por la que se modifica la Ley Orgánica 6/2001, de 21 de diciembre, de Universidades (B.O.E. de 13-IV-2007), p. 16241-60.

9. Nogueira-López A. Régimen jurídico de la selección del profesorado universitario. Barcelona: Atelier; 2004.

10. Llei $1 / 2003$, de 19 de febrer, d'Universitats de Catalunya (D.O.G.C. de 20-II-2003), p. 3326-45. URL: http://www. gencat.cat/diari/3826/03049128.htm.

11. Ley $15 / 2003$, de 22 de diciembre, Andaluza de Universidades (B.O.J.A. de 31-XII-2003), p. 27.452-74. URL: http:// www.juntadeandalucia.es/boja/boletines/2003/251/d/ updf/d3.pdf.

12. Ley $3 / 2004$, de 23 de febrero, del Sistema Universitario Vasco (B.O.P.V. de 12-III-2004, Suplemento). URL: http://www.euskadi.net/cgi-bin_k54/bopv_20?c\&f= 20040312\&s $=2004050$.

13. Decret $104 / 2002$, de 2 d'agost, pel qual es regula el règim jurídic i retributiu del personal docent i investigador contractat de la Universitat de les Illes Balears (B.O.I.B. de 08-VIII-2002), p. 13405-9. URL: http://boib.caib.es/ pdf/2002095/mp13405.pdf. 
14. Decreto $65 / 2003$, de 8 de mayo, por el que se aprueban los Estatutos de la Universidad de Extremadura (D.O.E. Extraordinario n. ${ }^{\circ} 3$ de 23-V-2003). URL: http://doe.juntaex.es/ultimosdoe/mostrardoe.php?fecha $=20030523$.

15. Recurso de inconstitucionalidad n. ${ }^{\circ} 3280-2003$, promovido por el Presidente de Gobierno, contra varios preceptos de la Ley del Parlamento de Cataluña 1/2003, de 19 de febrero de Universidades (B.O.E. de 14-VI-2003), p. 22949.

16. Tribunal Constitucional. Auto n. ${ }^{\circ} 350 / 2003$, de 29 de octubre de 2003. URL: http://www.tribunalconstitucional. es/AUTOS2003/ATC2003-350.html.

17. Recurso de inconstitucionalidad n. ${ }^{\circ}$ 3799-2004, promovido por el Presidente del Gobierno, contra los artículos 15.1.b) y primer inciso del párrafo c); 20.1c; 21.2d; 22.2; 27.2; 46.1c) y d); el inciso 'con carácter exclusivo' del artículo $6.1 ; 113.1$ y disposiciones transitorias segunda y tercera de la Ley 3/2004, de 25 de febrero, del Sistema Universitario Vasco (B.O.E de 3-VIII-2004), p. 27900.

18. Tribunal Constitucional. Auto n. ${ }^{\circ} 428 / 2004$, de 10 de noviembre de 2004. URL: http://www.tribunalconstitucional.es/autos2004/ATC2004-428.html.

19. Proyecto de Ley $121 / 000101$ Orgánica por la que se modifica la Ley Orgánica 6/2001, de 21 de diciembre, de Universidades. Enmiendas e índice de enmiendas al articulado. Boletín Oficial de las Cortes Generales. Congreso de los Diputados. VIII Legislatura, Serie A, n. ${ }^{\circ}$ 101-9 (28-XI-2006), p. 31-185.

20. Proyecto de Ley $621 / 000083$ Orgánica por la que se modifica la Ley Orgánica 6/2001, de 21 de diciembre, de Universidades. Dictamen de la Comisión. Boletín Oficial de las Cortes Generales. Senado. VIII Legislatura, Serie II, n. ${ }^{\circ}$ 83(e) (16-III-2007), p. 153-81.

21. Tribunal Constitucional. Auto n. ${ }^{\circ} 46 / 2007$, de 13 de febrero de 2007. URL: http://www.tribunalconstitucional. es/autos2007/ATC2007-046.html.

22. Tribunal Constitucional. Auto n. ${ }^{\circ} 72 / 2007$, de 27 de febrero de 2007. URL: http://www.tribunalconstitucional. es/autos2007/ATC2007-072.html.

23. Decreto 303/2003, de 11-11-2003, sobre régimen de personal docente e investigador contratado de la Universidad de Castilla-La Mancha (D.O.C.M. de 14-XI-2003), p. 18204-8. URL: http://docm.jccm.es/portaldocm/verDiarioAntiguo.do?ruta=2003/11/14.

24. Decreto 153/2002, de 12 de septiembre, sobre el régimen del personal docente e investigador contratado por las universidades públicas de Madrid y su régimen retributivo (B.O.C.M. de 19-IX-2002), p. 11-6. URL: http://www. madrid.org/cs/Satellite?blobcol=seccionpdf\&blobheader =application\%2Fpobkey=id\&blobtable=CM_Seccion_B OCM\&blobwhere $=1114173603119 \&$ ssbinary $=$ true.

25. Decret 174/2002, de 15 d’octubre, del Govern Valencià, sobre Règim i Retribucions del Personal Docent i Investigador Contractat Laboral de les Universitats Públiques Valencianes i sobre Retribucions Addicionals del Professorat Universitari (D.O.G.V. de 22-X-2002), p. 26198-211. URL: https://www.docv.gva.es/portal/ portal/2002/10/22/pdf/doc/2002_11297.pdf.

26. Decreto 10472003 , de 29 de agosto, por el que se regula el régimen jurídico y retributivo del personal docente e investigador contratado por la Universidad de La Rioja (B.O.R. de 04-IX-2003). URL: http://www.iustel.com/v2/ diario_del_derecho/noticia.asp?ref_iustel=1002349.

27. Decreto 84/2003, de 29 de abril, del Gobierno de Aragón, por el que se regula el régimen jurídico y retributivo del personal docente e investigador contratado de la Universidad de Zaragoza (B.O.A. de 29-V-2003). URL: http://benasque.aragob.es:443/cgibin/brscgi?cmd =ve rdoc $\&$ base $=$ bole $\&$ piece $=$ bole $\&$ docr $=4 \&$ sec $=$ busqued a_fech \&rng=200\&separador=\&\&@publ- e=20030519.

28. Decreto $94 / 2002$, de 8 de julio, por el que se regula el régimen del personal docente e investigador contratado de la Universidad de Extremadura (D.O.E. de 1-VII2002), p. 8854-60. URL: http://doe.juntaex.es/pdfs/ doe/2002/800O/02040106.pdf.

29. Decreto 140/2002, de 7 de octubre, sobre el régimen del personal docente e investigador contratado y sobre los complementos retributivos del profesorado de las Universidades Canarias (B.O.C. de 18-X-2002), p. 17058-67. URL: http://www.gobiernodecanarias.org/boc/2002/ 139/boc-2002-139.pdf.

30. Decreto n. ${ }^{\circ}$ 150/2003, de 25 de julio, sobre el régimen jurídico y retributivo del personal docente e investigador contratado de las Universidades Públicas de la Región de Murcia (B.O.R.M. de 02-VIII-2003), p. 14788-94. URL: http://www.carm.es/borm/documento?obj=anu\&id= 15597.

31. Decreto 266/2002, de 6 de septiembre, de contratación del profesorado universitario (D.O.G. de 17-IX-2002), p. 13713-7. URL: http://www.xunta.es/doc/Dog2002.nsf/5 168f626b2ff46e041256644003720d2/62dc40069c3b38bc 1256c36004fb081/\$FILE/17900D001P005.pdf.

32. Decreto $85 / 2002$, de 27 de junio, sobre el régimen del personal docente e investigador contratado en las Universidades Públicas de Castilla y León (B.O.C. y L. de 3-VII-2002), p. 8882-5. URL: http://bocyl.jcyl.es/

33. 'Acuerdo de la Asamblea General de la Conferencia de Rectores de las Universidades Españolas'. Modificación de la Ley Orgánica de Universidades. Propuestas sobre Profesorado (25-I-2006). URL: http://www.crue.org/boletines/boletin_n2/adjuntos/profesorado.pdf.

34. Plataforma Estatal de Profesores Contratados que iniciaron su carrera docente bajo la LRU. Manifiesto ante el proyecto de reforma de la Ley Orgánica 6/2001, de 21 
de diciembre, de Universidades (LOU) (noviembre de 2005). URL: http://www.cgt-uab.net/arxiu/documents/ manifiesto_estatal_contratados_lou.pdf.

35. Sección Sindical SIPU. Nota informativa (11/XI/2005). URL: http://www.api.uniovi.es/sipu/Comunicados\%20 SIPU\%20PDI/comunicado\%2011\%20\%2011\%20de\% 20noviembre\%20de\%202005.pdf.

36. Europa Press. Marcellán alerta de una posible diversidad' en la contratación de profesorado por las CCAA. URL: http://www.elmundo.es/universidad/2005/10/28/ actualidad/1130510580.html.

37. FETE-UGT. Comisión Ejecutiva Federal. Propuesta de FETE-UGT al borrador de la Ley Orgánica de Modificación de la Ley Orgánica 6/2001, de 21 de diciembre, de Universidades (18-XI-2005). URL: http://www.upo.es/ ugt/docu/prop_fete_borrador_mod_lou.pdf.

38. Real Decreto 989/2008, de 13 de junio, por el que se regula la contratación excepcional de profesores colaboradores (B.O.E. de 1-VII-2008), p. 28946-8.

39. Resolución de 7 de octubre de 2008, de la Dirección General de Universidades, por la que se determina el procedimiento para presentación de solicitudes de evaluación de la Agencia Nacional de Evaluación de la Calidad y Acreditación, así como los criterios de evaluación, para la figura de profesor colaborador, regulada por el Real Decreto 989/ 2008, de 13 de junio (B.O.E. de 29-X-2008), p. 43008-9.

40. Resolución de 19 de julio de 2007, del Rectorado, por la que se modifica la Resolución de 5 de abril de 2004, del Rectorado, por la que se aprueba la normativa para la contratación de profesorado de la Universidad de Extremadura (D.O.E. de 4-VIII-2004), p. 13451-3. URL: http:// doe.juntaex.es/pdfs/doe/2007/900O/07062349.pdf.

41. Resolución de 28 de noviembre de 2007, de la Dirección General de Universidades, por la que se modifica la de 26 de julio de 2005, que establece los criterios de acreditación de las figuras contractuales de Profesorado Universitario (B.O.J.A. de 12-XII-2007), p. 83. URL: http:// www.juntadeandalucia.es/boja/boletines/2007/243/d/ updf/d33.pdf.

42. Real Decreto 1052/2002, de 11 de octubre, por el que se regula el procedimiento para la obtención de la evaluación por la Agencia Nacional de Evaluación de la Calidad y Acreditación, y de su certificación, a los efectos de contratación de personal docente e investigador universitario. (B.O.E. de 12-X-2002), p. 36095-6.

43. Resolución de 17 de octubre de 2002, de la Dirección General de Universidades, por la que se publican los criterios generales de evaluación de la Agencia Nacional de Evaluación de la Calidad y Acreditación para la contratación de personal docente e investigador y se determina el procedimiento de solicitudes de evaluación o informe (B.O.E. de 30-X-2002), p. 38222-7.
44. Resolución de 24 de junio de 2003, de la Dirección General de Universidades, por la que se establece el procedimiento de solicitud de evaluación de la Agencia Nacional de Evaluación de la Calidad y Acreditación para la contratación de personal docente e investigador en los supuestos de solicitantes pertenecientes a cuerpos docentes universitarios o que se encontrasen habilitados de acuerdo con la Ley Orgánica de Universidades y se publican los criterios de evaluación a estos efectos (B.O.E. de 9-VII-2003), p. 26868-9.

45. Ministerio de Administraciones Públicas. Conflictividad entre el Estado y las Comunidades Autónomas (Boletín Informativo). Primer trimestre 2003, p. 60-3. URL: http: //www.map.es/documentacion/politica_autonomica/regimen_juridico/parrafo/016/document_es/3_trimes_ 2005_color_definitivo.pdf.

46. Conflicto positivo de competencias $n .^{\circ} 1130-2003$, promovido por el Gobierno de la Generalidad de Cataluña en relación con determinados preceptos del Real Decreto $1052 / 2002$, de 11 de octubre, por el que se regula el procedimiento para la obtención de la evaluación por la Agencia Nacional de Evaluación de la Calidad y Acreditación, y de su certificación, a los efectos de contratación de personal docente e investigador universitario (B.O.E. de 17-V-2003), p. 19022.

47. Carreras J. Evaluación de la calidad docente y promoción del profesorado $(\mathrm{V})$. Legislación universitaria española (c): desarrollo de la Ley Orgánica de Universidades (2002- 2005). Educ Med 2007; 10: 69-85.

48. ANECA. Informe del programa de evaluación de profesorado para la contratación ( 1 de enero de 2006-31 de diciembre de 2006). URL: http://www.aneca.es/active/ docs/pep_informeprograma_070716.pdf.

49. Pérez-Martínez F. 3,5 años de evaluación del profesorado universitario para la contratación en la ANECA. Encuentro ' 10 años de evaluación de la calidad en las universidades españolas: 1996-2006. Resultados y objetivos' Jaca, junio de 2006. URL: http://wzar.unizar.es/ actos/congresojaca/doc/pdf/F_Perez.pdf.

50. Resolución de 18 de febrero de 2005, de la Dirección General de Universidades por la que se modifican determinados aspectos del procedimiento de presentación de solicitudes de evaluación o informe de la Agencia Nacional de Evaluación de la Calidad y Acreditación para la contratación de personal docente e investigador, así como los criterios de evaluación, establecidos en las Resoluciones de 17 de octubre de 2002 y de 24 de junio de 2003, de la Dirección General de Universidades. (B.O.E. de 4-III-2005), p. 7875-7. URL: http://www.uji.es/bin/ infopdi/docs/aneca/np.pdf.

51. ANECA. Nuevo proceso de evaluación del profesorado para la contratación. URL: http://www.uji.es/bin/infopdi/docs/aneca/np.pdf. 
52. ANECA. Programa de evaluación de profesorado. Principios y orientaciones para la aplicación de los criterios de evaluación. URL: http://www.aneca.es/modal_eval/ pep_nuevo_orientaciones.html.

53. ANECA. Programa de evaluación de profesorado. Guía de ayuda al solicitante. URL: http://webs.uvigo.es/es-ct/ pep_nuevo_guiasolicitante.pdf.

54. ANECA. Programa de evaluación de profesorado. Procedimiento de selección de evaluadores de los comités de evaluación del programa de evaluación de profesorado. URL: http://www.uclm.es/organos/vic_profesorado/ documentacion/pep_nuevo_comites2.pdf.

55. ANECA. Informe del programa de evaluación de profesorado para la contratación. 2002-05. URL: http://www. aneca.es/active/docs/pep_informe_060221.pdf.

56. ANECA. Informe del programa de evaluación de profesorado para la contratación (junio de 2005-mayo de 2006). URL: http://www.aneca.es/active/docs/pep_informeanual_060710.pdf.

57. ANECA. Memoria de actividades. Enero-diciembre de 2007. URL: http://www.aneca.es/publicaciones/docs/ memoria07_081001.pdf.

58. ANECA. Programa de evaluación de profesorado para la contratación. Principios y orientaciones para la aplicación de los criterios de evaluación (V3 15/05/2007). URL: http://www.aneca.es/active/docs/pep_nuevo_principios_070515.pdf.

59. ANECA. Programa de evaluación de profesorado para la contratación. Guía de ayuda al solicitante (V3 07/06/ 2007). URL: http://www.aneca.es/active/docs/pep_nuevo_guiasolicitante_070607.pdf.

60. ANECA. Programa de evaluación de profesorado para la contratación. Respuestas a preguntas frecuentes (V2 13/06/2007). URL: http://www.aneca.es/active/docs/ pep_nuevo_faq_070613.pdf.

61. ANECA. Procedimiento para la constitución y renovación de la comisión y comités de evaluación del PEP (V3.0 12/04/2007). URL: http://www.aneca.es/active/ docs/pep_comites_procedimiento_071023.pdf.

62. ANECA. Resultados del programa de evaluación de profesorado para la contratación (PEP). 1 enero-31 de diciembre de 2007. URL: http://www.aneca.es/active/docs/ pep_resultados2007_080923.pdf.

63. ANECA. Resultados del programa de evaluación de profesorado para la contratación (PEP). 1 enero-31 de diciembre de 2008. URL: http://www.aneca.es/active/docs/ pep_resultados2008_090220.pdf.

64. Resolución de 28-03-2007, de la Agencia de Calidad Universitaria de Castilla-La Mancha, por la que se dispone la publicación del Acuerdo del Consejo de la Agencia de Calidad Universitaria de Castilla-La Mancha de 1212-2006 por el que se regula el procedimiento de presen- tación de solicitudes para la previa evaluación o emisión de informes para la contratación de personal docente e investigador, así como los criterios de evaluación (D.O.C.M. de 24-IV-2007), p. 10021-35. URL: http:// www.acucm.es/files/legislation/pr_00006_158840_1.pdf.

65. Resolución de 26 de julio de 2005, de la Dirección General de Universidades, por la que se establecen los criterios de acreditación para las figuras contractuales de profesorado universitario (B.O.J.A. de 8-VIII-2005), p. 7-9. URL: http://www.juntadeandalucia.es/boja/boletines/ 2005/153/d/updf/d1.pdf.

66. Agencia para la Calidad del Sistema Universitario de Castilla y León. Procedimiento para la previa evaluación o emisión de informe de las figuras de Profesorado Contratado y la evaluación del Profesorado de las Universidades Privadas en posesión del título de doctor. URL: http://www.acsucyl.es:8080/acsucyl/export/system/modules/org.opencms.module.acucyl/elements/galleries/ galeria_descargas/Manual_procedimiento_contratados.pdf.

67. Orden de 1 de abril de 2003 por la que se establecen los criterios generales de informe y evaluaciones de la Agencia para la Calidad del Sistema Universitario de Galicia para la contratación de personal docente e investigador (D.O.G. de 21-IV-2003), p. 4938-40. URL: http://www. xunta.es/doc/Dog2003.nsf/5168f626b2ff46e0412566440 03720d2/9f2dc6ad7a57ce42c1256d0a0054a5f5/\$FILE/0 7600D003P010.pdf.

68. Orden de 23 de junio de 2004 por la que se aprueba el protocolo de evaluación e informe para la contratación de profesorado por las universidades integrantes del Sistema Universitario de Galicia (D.O.G. de 5-VII-2004), p. 9665-75. URL: http://www.xunta.es/doc/Dog2004.nsf/5 168f626b2ff46e041256644003720d2/210122ff55451f79c 1256ec5006117b3/\$FILE/12800D002P009.pdf.

69. Axencia para a Calidade do Sistema Universitario de Galicia. Acreditación profesorado. Criterios de informe e avaliación. URL: http://www.acsug.es/galego/webs/evaconcriterios.php.

70. Acord 2/2007, del Consell de Direcció de l'Agència de Qualitat Universitària de les Illes Balears, pel qual es fan públics els criteris per avaluar i emetre informes de cada una de les figures contractuals de professor contractat doctor, professor ajudant doctor i professor colllaborador (B.O.I.B. de 15-IX-2007), p. 186-92. URL: http://www. aquib.org/cat/pdf/convocatories/2007/acord2_boib.pdf.

71. Agencia Canaria de Evaluación de la Calidad y Acreditación Universitaria. Acreditación de cara a la contratación de profesorado por las universidades canarias. URL: http://www.acecau.org/es/acreditacionprofesorado.html.

72. Gobierno de Canarias. Consejería de Educación, Cultura y Deportes. Protocolo para la evaluación de solicitudes de acreditación de cara a la contratación de profesorado 
por las universidades canarias. URL: http://www.acecau. org/files//documentos/Acreditacion\%20profesorado/ ACECAU_protocolo_acreditacion.pdf.

73. Acuerdo de 29 de septiembre de 2006, del Comité de Dirección de la Agencia de Calidad, Acreditación y Prospectiva de las Universidades de Madrid, por el que se modifican los criterios de evaluación, el baremo para la contratación de profesorado universitario por las universidades de Madrid y el procedimiento de evaluación, vigentes en virtud del acuerdo de 21 de noviembre de 2005 (B.O.C.M. de 26-X-2006), p. 19-29. URL: http:// www.madrid.org/cs/Satellite?blobcol=seccionpdf\&blo bheader=application $\% 2 \mathrm{Fpdf} \&$ blobkey=id\&blobtable= CM_Seccion_BOCM\&blobwhere $=1142318632240 \&$ ssb inary=true.

74. Agencia de Calidad, Acreditación y Prospectiva de las Universidades de Madrid. Sistema de evaluación del profesorado universitario para su contratación por las universidades de Madrid. Octubre de 2007. URL: http:// www.madrid.org/cs/Satellite?c=CM_Publicaciones_FA $\& c i d=1142458213698 \&$ idConsejeria $=1109266187254 \&$ idListConsj $=11092654447$ 10\&idOrganismo $=11092662$ $27448 \&$ language $=$ es\&pagename $=$ ComunidadMadrid $\%$ 2FEstructura\&sm $=1109266101003$.

75. Resolució de 2 de juliol de 2007, de la Direcció General d'Universitats i d'Educació Superior, per la qual es publica l'Acord de 18 de juny de 2007, de la Comissió Valenciana d’Acreditació i Avaluació de la Qualitat del Sistema Universitari Valencià (D.O.C.V. de 11-VII2007), p. 28971-6. URL: http://www.docv.gva.es/portal/ portal/2007/07/11/pdf/2007_9101.pdf.

76. Resolució de 4 de juny de 2008, del President de l'Agència Valenciana d'Avaluació i Prospectiva, per la qual s’aprova la convocatòria corresponent a l’any 2008, d’avaluació per a la contractació de professorat en les universitats valencianes, en les figures de professora o professor contractat doctor, professora o professor ajudant doctor o professora o professor d'universitat privada (D.O.C.V. de 10-VI-2008), p. 66049-89. URL: http://www.docv.gva.es/ portal/portal/2008/06/10/pdf/2008_7140.pdf.

77. AQU Catalunya. Evaluación del profesorado universitario. Profesor agregado. URL: http://www.aqu.cat/doc/ doc_35706928_1.pdf.

78. AQU Catalunya. Evaluación del profesorado universitario. Catedrático URL: http://www.aqu.cat/doc/doc_ 31080367_1.pdf.

79. Resolució UNI/1239/2004, de 26 d'abril, per la qual es dóna publicitat a l'acord relatiu al procediment per a l'emissió de les certificacions o avaluacions de l'Agència per a la Qualitat del Sistema Universitari de Catalunya relatives a l'activitat docent per a la Contractació com a catedràtic $\mathrm{o}$ com a professor o professora agregat, d'acord amb la Llei 1/2003, de 19 de febrer, d'Universitats de Catalunya (D.O.G.C. de 5-V-2004), p. 8541-3. URL: http:// www.gencat.cat/diari/4126/04118106.htm.

80. AQU Catalunya. Certificación de la actividad docente. URL: http://www.aqu.cat/activitats/professorat_merits/ activitat_docent/certificat_activitat_docent/index_es.html.

81. AQU Catalunya. Resultats globals de l'activitat d'avaluació de professorat 2003-2007. URL: http://www.aqu.cat/ actualitat/noticies/n9529.html.

82. AQU Catalunya. Resultats de la primera convocatòria de 2008 d'emissió d'acreditacions de recerca i de recerca avançada. URL: http://www.aqu.cat/actualitat/noticies/59243459.html.

83. AQU Catalunya. Resultats de la segona convocatòria de 2008 d'emissió d'acreditacions de recerca i de recerca avançada. URL: http://www.aqu.cat/actualitat/noticies/51948071.html.

84. AQU Catalunya. Memòries d’activitas (2004-2008). URL: $\mathrm{http} / / /$ www.aqu.cat/publicacions/memories_anuals_es.html.

85. Arboix E. Resultats de l'enquesta de satisfacció de l'avaluació del professorat 2008. AQU de Catalunya. El Butlletí 2009; 42. URL: http://www.aqu.cat/elButlleti/butlleti42/articles2.html.

86. Decreto 14972008 , de 29 de julio, por el que se aprueban los criterios a utilizar en la evaluación, acreditación y certificación de Uniqual, Agencia de Evaluación de la Calidad y Acreditación del Sistema Universitario Vasco, del personal docente e investigador contratado de la Universidad del País Vasco, del profesorado de las universidades privadas en posesión del título de doctor, y para obtener el informe previo a la contratación de profesorado colaborador y asociado de la Universidad del País Vasco (B.O.P.V. de 11-VIII-2008), p. 20691-745. URL: http://www.euskadi.net/cgi-bin_k54/bopv_20?c\&f $=20080811 \& \mathrm{a}=200804687$.

87. UNIQUAL. Acreditación del profesorado. Criterios específicos de evaluación. Profesor pleno. URL: http://pdf. uniqual.org/entry/content/113/Profesor_pleno.pdf.

88. UNIQUAL. Acreditación del profesorado. Criterios específicos de evaluación. Profesor agregado. URL: http://pdf. uniqual.org/entry/content/107/Profesor_agregado.pdf.

89. Agencia de Calidad y Prospectiva Universitaria de Aragón. Acreditación. URL: http://portal.aragon.es/portal/ page/portal/agenciacalidad/evaluaciones/profesorado_/ acreditaci\%C3\%B3n.

90. AQU Catalunya. Las agencias de calidad debaten sobre el procedimiento y los criterios de evaluación del profesorado (29-04-2005). URL: http://www.aqu.cat/actualitat/noticies/n3729_es.html.

91. Encuentro de agencias de calidad, 25 y 26 de abril de 2005. Comunicado. URL: http://qualitas.usal.es/PDF/ Comunicado_agencias_chinchon. 
92. AQU Catalunya. Se constituye la Red Española de Agencias de Calidad Universitaria (17-10-2006). URL: http:// www.aqu.cat/actualitat/noticies/n6829_es.html.

93. Acuerdo constitutivo de la Red Española de Agencias de Calidad Universitaria (REACU). URL: http://www. acsucyl.es:8081/acsucyl/export/system/modules/org. opencms.module.acucyl/elements/galleries/galeria_descargas/actareacu.pdf.

94. AQU Catalunya. Las agencias de calidad de Aragón y Valencia se adhieren a la REACU (13-04-2007). URL: http://www.aqu.cat/actualitat/noticies/n8129_es.html.

95. ACUCyL-REACU. Simposio 'Armonización de la acreditación del profesorado. Tordesillas, 9 y 10 de octubre de 2006. Documentos de trabajo elaborados por las agencias que integran la Red Española de Agencias de Calidad Universitaria. URL: http://www.acsucyl.es:8081/acsucyl/ export/system/modules/org.opencms.module.acucyl/ elements/galleries/galeria_descargas/Tordesillas.pdf.

96. AQU. Documento interno. 2009.

97. Conveni marc entre el Departament d'Universitats, Recerca i Societat de la Informació, les Universitats Públiques i l'Agència per a la Qualitat del Sistema Universitari de Catalunya per al desenvolupament del Pla Jaume Serra i Junter de professorat contractat permanent (1-VIII-2003). URL: http://www.gencat.cat/diue/doc/ doc_31219235_1.pdf.

98. Ministerio de Ciencia e Innovación. Estadística de personal de las universidades. URL: http://web.micinn.es/ contenido.asp menu $1=3 \&$ menu $2=0 \&$ menu $3=\& \operatorname{dir}=04$ Universidades/02@EstInf/02@Est/02-EstadisticaP/10PDInvUniv.

99. De la Oliva A. Análisis crítico de la teoría y la praxis de la 'ANECA' (23-X-2003). URL: http://www.profesionales pcm.org/ProblemaEspanol/CeseANECA.html\#documentos.

100. De la Oliva A. ANECA: evaluaciones ilegales del profesorado y recurso de alzada (5-XI-2003). URL: http:// www.profesionalespcm.org/ProblemaEspanol/CeseANECA.html\#documentos.

101. Crespo I. Respuesta a Andrés de la Oliva (5-XI-2003). URL: http://web.udl.es/rectorat/vqp/butlletins/aneca/ cartaoliva.pdf.

102. De la Oliva A. ANECA: cuanto más la defiende, peor la pone (falsedades, incoherencias, contradicciones) (A propósito de una 'respuesta' del director de la agencia) (17-XI-2003). URL: http://acapiun.idecnet.com/downloads/001.doc.

103. De la Oliva A. Manifiesto: un cambio necesario en la universidad (9-XII-2003). URL: http://profesores.universia.es/carrera-academica/otros-recursos/opinion/ 20031209_manifiesto_cambio_necesario.htm.

104. Asenjo M. Profesores de medio centenar de universidades apoyan una propuesta para cambiar la ANECA. ABC, de 20-I-2004.

105. Conferencia de Rectores de las Universidades Españolas. URL: http://www.crue.org/UNIVERSIDADES/. 